\title{
Analisis Likes to Subscriber Ratio Youtube Pada 5 Brand Sepatu Terkenal di Dunia
}

\author{
Made Irvan Sastra Abenk \\ irvanabenk75@gmail.com
}

\begin{abstract}
YouTube is a video sharing website created by three former Paypal employees, there are Steve Chen, Chad Hurley and Jawed Karim in February 2005. This website allows users to upload, watch and share videos. The first video uploaded on the site is titled "Me at the zoo" which shows the YouTube co-founder at the San Diego Zoo. YouTube is also one of the largest social media applications that are often used to market an item by well-known brands. There are 5 famous shoe brands in the world that have used Youtube as a marketing medium, namely : Vans, Adidas, Nike, New Balance, and Converse. This study has a purpose, namely to calculate the credibility of the YouTube accounts of 5 Famous Shoe Brands in the World. The method used for this research is quantitative exploratory method. The results of this study indicate that the New Balance shoe brand is ranked first and has the best account performance credibility.
\end{abstract}

\begin{abstract}
ABSTRAK
YouTube adalah sebuah situs web berbagi video yang dibuat oleh tiga mantan karyawan Paypal, yaitu Steve Chen, Chad Hurley dan Jawed Karim pada Februari 2005. Situs web ini memungkinkan pengguna mengunggah, menonton, dan berbagi video. Video pertama yang diunggah di situs ini berjudul "Me at the zoo" yang menayangkan salah satu pendiri YouTube saat berada di Kebun binatang San Diego. YouTube juga menjadi salah satu aplikasi media sosial terbesar yang sering digunakan untuk melakukan pemasaran suatu barang oleh brand ternama. Adapun 5 brand sepatu terkenal di dunia yang sudah memanfaatkan Youtube sebagai media pemasaran, yaitu : Vans, Adidas, Nike, New Balance, dan Converse. Penelitian ini memiliki tujuan yaitu untuk menghitung kredibilitas dari akun YouTube 5 Brand Sepatu Terkenal di Dunia. Metode yang digunakan untuk penelitian ini yaitu metode eksploratif kuantitatif. Hasil dari penelitian ini menunjukkan bahwa brand sepatu New Balance mendapatkan peringkat pertama dan memiliki kredibilitas performa akun yang terbaik.
\end{abstract}

Keyword : Credibility Account YouTube ; Social Media Marketing ; Social Media YouTube ; Likes to Subscriber Ratio ; Brand Sepatu Terkenal di Dunia. 


\section{PENDAHULUAN}

Seiring waktu, sudah tidak terasa lagi bahwa di zaman ini perkembangan teknologi sudah begitu pesat. Zaman yang penuh akan namanya kecanggihan dan apapun serba praktis. Dimana semua berlomba-lomba untuk menciptakan hal yang baru untuk mempermudah perkerjaannya, salah satunya adalah media sosial. Media sosial memberikan pengaruh yang cukup besar, karena sering dijadikan sarana berkomunikasi dan bertukar informasi dengan mudah.

Perkembangan pesat yang sudah terjadi ini, memberikan dampak terhadap situs-situs komunikasi. Salah satu contoh media sosial yang sering digunakan yaitu YouTube. YouTube merupakan situs web berbagi video yang dibuat oleh tiga mantan karyawan Paypal. Youtube memungkinkan penggunanya untuk memuat, menonton, dan berbagi video secara gratis.

Di dunia, YouTube dinobatkan sebagai media sosial terpopuler. YouTube berhasil menjaring dua miliar pengguna aktif tiap bulan, faktanya hampir 43\% dari semua pengguna internet global mengakses YouTube setiap bulan. Pengguna aktif hariannya bahkan lebih dari satu milliar jam konten dikonsumsi di YouTube setiap hari. Dengan jumlah pengguna tersebut tentu YouTube dapat memberikan peluang bagi brand untuk dijadikan sebagai sarana media sosial pemasaran. Sudah banyak brand terkenal menjadikan YouTube sebagai media pemasaran mereka, contohnya seperti brand sepatu ternama. Berikut 5 Brand Sepatu Terkenal di Dunia, yaitu : Vans, Adidas, Nike, New Balance, dan Converse (Begini Sejarah 5 Brand Sepatu Terkenal Dunia, n.d.).

Penelitian ini menggunakan metode eksploratif kuantitatif, dan akan menghitung menggunakan rasio-rasio yang ada pada YouTube. Pada penelitian (Permana, 2021) menjelaskan bahwa terdapat 10 rasio yang ada pada sosial media YouTube dan relevan digunakan sebagai media ukur kredibilitas akun yang ada. Penelitian ini hanya berfokus untuk menghitung kredibilitas Likes to Subscriber pada 5 Brand Sepatu Terkenal di Dunia. Berikut 5 Brand Sepatu Terkenal di Dunia, yaitu : Vans, Adidas, Nike, New Balance, dan Converse (Begini Sejarah 5 Brand Sepatu Terkenal Dunia, n.d.). Tujuan dari penelitian ini adalah mengetahui kredibilitas performa dari akun YouTube 5 Brand Sepatu Terkenal di Dunia menggunakan Likes to Subsriber Ratio. 


\section{TINJAUAN PUSTAKA}

Saat ini semakin beragam setiap orang menawarkan produk-produk baik melalui media cetak, online maupun media sosial. Salah satu bentuk media sosial yang selalu menawarkan produk terbaru adalah YouTube. Melalui YouTube setiap orang bisa mendapatkan berbagai informasi, hiburan dan informasi iklan produk terbaru.

YouTube adalah sebuah situs web video sharing (berbagi video) yang populer dimana para pengguna dapat memuat, menonton, dan berbagi klip video secara gratis. Didirikan pada bulan februari 2005 oleh 3 orang mantan karyawan PayPal, yaitu Chad Hurley, Steve Chen dan Jawed Karim. Umumnya video-video di YouTube adalah video klip film, TV, serta video buatan para penggunanya sendiri. (Thanissaro \& Kulupana, 2015).

Youtube dianggap memiliki potensi yang besar bagi pengiklan, mengingat Youtube memiliki segmen yang lebih pasti. Youtube dengan penyedia layanan video terbesar sekarang ini dimiliki oleh Google, dimana pengguna bisa memuat, melihat dan berbagi video secara gratis dengan konten beragam. (Yunita et al., 2019). Dalam sehari jumlah pengunjung YouTube dapat mencapai lebih dari 30 juta. Hal inilah yang menyebabkan banyak orang berlomba-lomba untuk menciptakan konten-konten yang menarik perhatian pengguna YouTube. Berbagai cara dilakukan untuk menciptakan konten yang menarik dan salah satu teknik pemasaran yang dilakukan yakni memperkenalkan produk melalui channel YouTube tersebut. (Sinaga, 2020).

Dengan begitu, YouTube menjadi salah satu media sosial yang cocok digunakan di industri pengiklanan. Mengingat pengguna YouTube yang seiring waktu terus bertambah, tidak sedikit brand sepatu ternama menggunakan YouTube sebagai media promosi brand mereka.

\section{METODE PENELITIAN}

Penelitian ini menggunakan metode eksploratif kuantitatif untuk mencari tahu kredibilitas dari perfoma akun YouTube dari 5 brand sepatu terkenal di dunia. Penelitian eksploratif adalah salah satu jenis penelitian sosial yang tujuannya untuk memberikan sedikit definisi atau penjelasan mengenai konsep atau pola yang digunakan dalam penelitian (Wikipedia, n.d.).

Tujuan dari penelitian ini yaitu untuk mengetahui nilai kredibilitas dari performa akun YouTube dari 5 brand sepatu terkenal di dunia. Ada beberapa langkah yang harus dilakukan dalam melakukan penelitian ini, sehingga mampu menentukan peringkat pertama akun YouTube brand sepatu terkenal di dunia yang memiliki performa paling baik. Langkah-langkah yang dilakukan, diantaranya yaitu :

\section{Melakukan Eksplorasi Pada Website Untuk Menentukan Objek yang Akan Dianalisa.}

Eksplorasi ini dilakukan pada beberapa halaman website yang menyediakan informasi mengenai objek-objek yang akan diteliti. Setelah eksplorasi yang dilakukan selesai, sehingga ditemukan nama-nama brand sepatu terkenal di dunia yang akan dijadikan objek penelitian. Setelah melakukan eksplorasi pada halaman website, maka langkah 
selanjutnya yaitu mencari nama akun YouTube dari masing-masing brand sepatu, dan pastikan semua brand memiliki akun media sosial berupa YouTube.

2. Menghitung Nilai Rata-Rata Variable Dari 5 Brand Sepatu Terkenal di Dunia.

Pada langkah ini, peneliti menghitung nilai variable likes dan variable subscriber. Variable merupakan setiap karakteristik, jumlah, atau kuantitas yang dapat diukur atau dihitung (Hatch dan Farhandy 2015). Untuk menghitung nilai rata-rata dari variable likes dan variable subscriber yaitu dengan cara mengambil 10 postingan kemudian dihitung sehingga akan menemukan nilai rata-rata dari masing-masing variable.

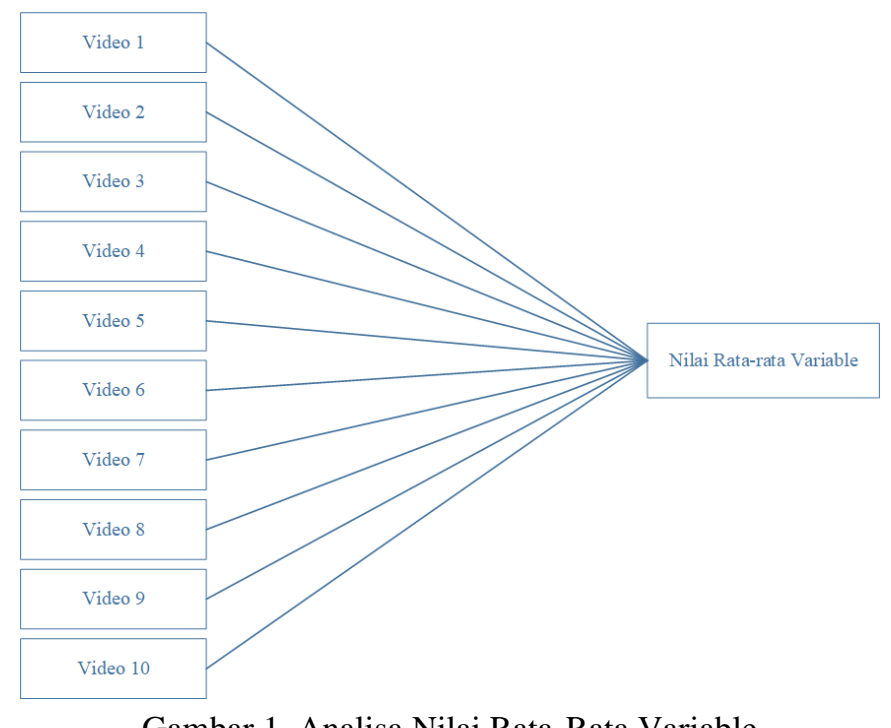

Gambar 1. Analisa Nilai Rata-Rata Variable

3. Menghitung Nilai Kredibilitas Rasio.

Untuk menghitung nilai kredibilitas dari likes to subscriber ratio, maka peneliti menggunakan cara membagi nilai variable pertama dengan nilai variable kedua. Jika likes memiliki nilai 10 dan subsriber memiliki nilai 50, maka cara menghitungnya yaitu $10: 50=0,2$. Dengan begitu nilai dari likes to subscriber ratio adalah 0,2.

\section{Menentukan Peringkat Pada Akun YouTube.}

Pada langkah terakhir, peneliti menentukan peringkat pada masing-masing rasio yang sudah didapat. Pada penentuan peringkat perlu melihat karakteristik dari rasio yang diteliti. Jika karakteristik raiso tinggi, maka objek yang memiliki nilai tertinggi akan mendapatkan angka 5 (lima) dan objek yang memiliki nilai terendah akan mendapatkan angka 1 (satu). Namun jika karakteristik raiso rendah, maka objek yang memiliki nilai terendah akan mendapatkan angka 5 (lima) dan objek yang memiliki nilai tertinggi akan mendapatkan angka 1 (satu). Setelah mendapatkan hasil kredibilitas ratio maka dapat disimpulkan objek yang mana mendapatkan peringkat 1 (pertama) sampai dengan peringkat 5 (kelima).

\section{HASIL DAN PEMBAHASAN}


Akun YouTube dari 5 Brand Sepatu Terkenal di Dunia, diantaranya :

1. Vans

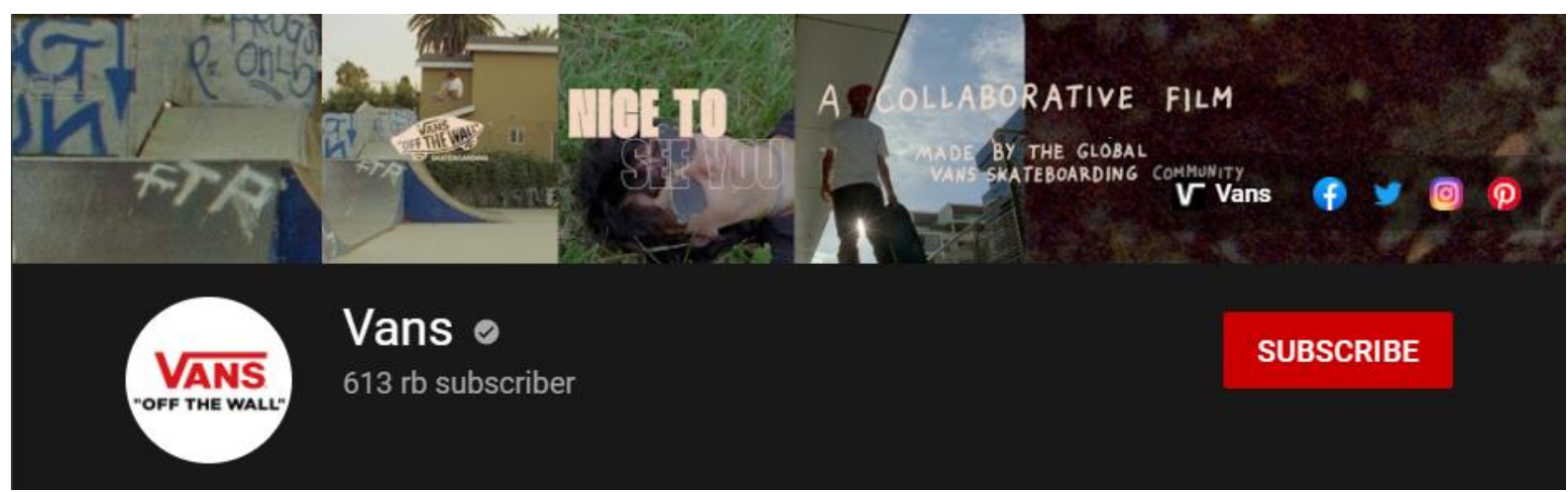

Gambar 1. Akun YouTube Vans

Sumber : https://www.youtube.com/user/VansShoes66 (di akses pada 21-10-2021)

\section{Adidas}

\section{adidas \\ IMPOSSIBLE \\ IS NOTHING}

A adidas.com f $y$ (ㅇ)

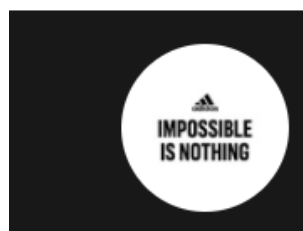

\section{adidas $\bullet$}

931 rb subscriber

Gambar 2. Akun YouTube Adidas

Sumber : https://www.youtube.com/user/adidas (di akses pada 21-10-2021)

\section{Nike}




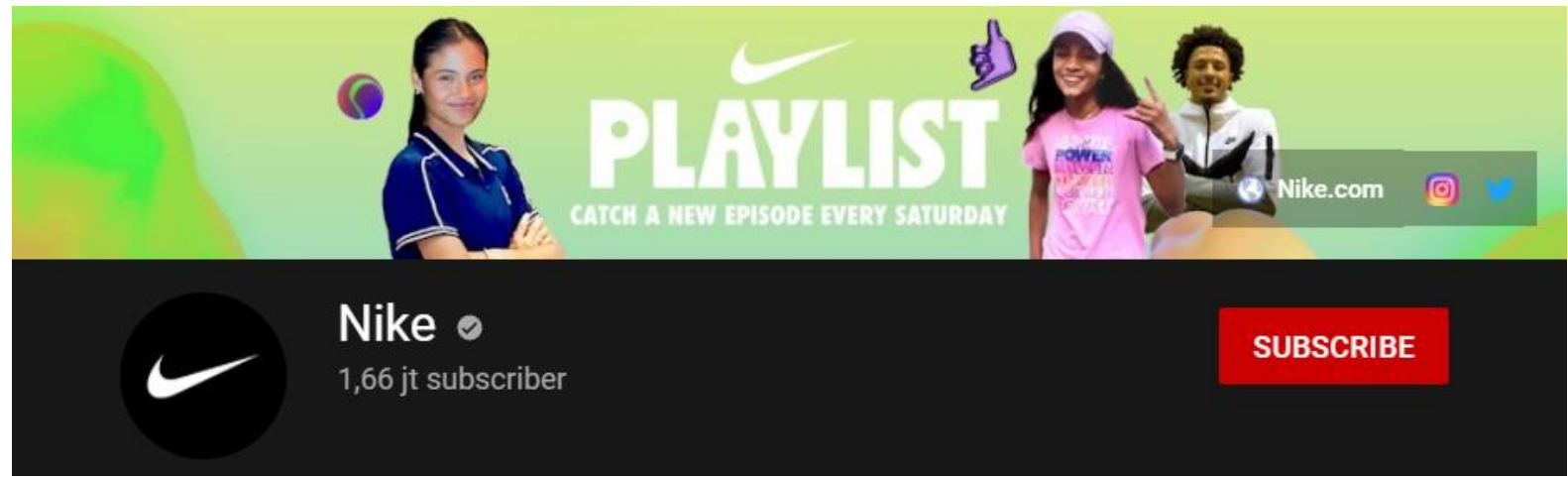

Gambar 3. Akun YouTube Nike

Sumber : https://www.youtube.com/c/nike (di akses pada 21-10-2021)

\section{New Balance}

\section{WE GOT NOW \\ (J) New Balance (0) f}

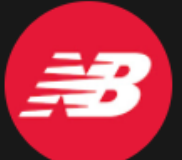

newbalance

113 rb subscriber

Gambar 4. Akun YouTube New Balance

Sumber : https://www.youtube.com/user/newbalance (di akses pada 21-10-2021) 


\section{Converse}

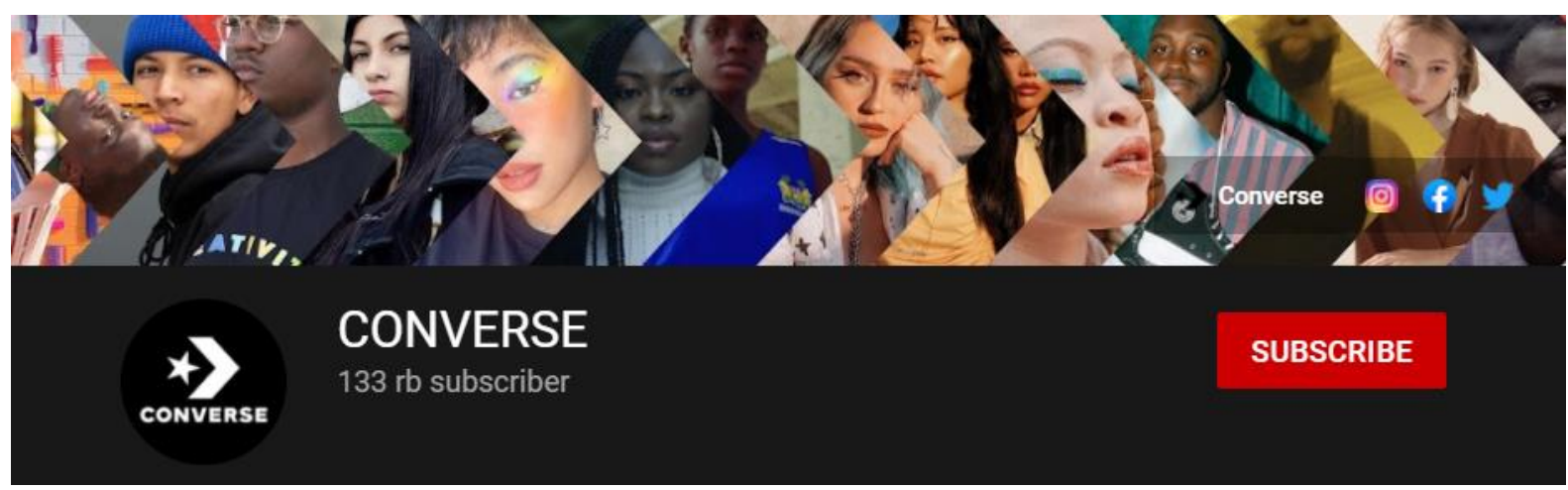

Gambar 5. Akun YouTube Converse

Sumber : https://www.youtube.com/c/converse (di akses pada 21-10-2021)

Dari kelima akun YouTube dari 5 brand sepatu terkenal di dunia, peneliti menemukan nilai dari masing-masing variabel yang ada untuk menghitung rasio Likes to Subscriber dari setiap akun. Pada akun YouTube terdapat 6 variabel, diantaranya yaitu :

1. Post

2. Likes

3. Dislikes

4. Viewers

5. Comments

6. Subscriber

Dari keenam variabel tersebut, peneliti hanya berfokus untuk menemukan hasil dari 2 variabel, yaitu :

1. Likes

2. Subscriber

Dari kedua variabel tersebut kemudian dianalisa sehingga menemukan nilai rata-rata dari variabel likes dan variabel subscriber. Untuk menghitung nilai rata-rata dari variabel likes dan variabel subscriber yaitu dengan cara mengambil 10 postingan kemudian dihitung sehingga menemukan nilai rata-rata dari masing-masing variabel. Berikut merupakan tabel nilai rata-rata dari masing-masing brand sepatu terkenal di dunia, yaitu : 
Tabel 1. Analisa Nilai Rata-Rata Nilai Variabel Likes dan Subscriber Akun YouTube Vans

\begin{tabular}{|l|l|l|}
\hline No & Likes & Subscriber \\
\hline 1 & 87 & \\
\hline 2 & 62 & \\
\hline 3 & 3.700 & \\
\hline 4 & 87 & \\
\hline 5 & 201 & \\
\hline 6 & 201 & \\
\hline 7 & 984 & \\
\hline 8 & 184 & \\
\hline 9 & 21.000 & $\mathbf{6 1 2 . 0 0 0}$ \\
\hline 10 & 44 & $\mathbf{2 . 6 5 5}$ \\
\hline Total & \multicolumn{3}{|l|}{ Sumber : Pengolah Data Excel } \\
\hline
\end{tabular}

Tabel 2. Analisa Nilai Rata-Rata Nilai Variabel Likes dan Subscriber Akun YouTube Adidas

\begin{tabular}{|l|l|l|}
\hline No & Likes & Subscriber \\
\hline 1 & 42 & \\
\hline 2 & 576 & \\
\hline 3 & 28 & \\
\hline 4 & 17 & \\
\hline 5 & 27 & \\
\hline 6 & 476 & \\
\hline 7 & 33 & \\
\hline 8 & 27 & \\
\hline 9 & 84 & 931.000 \\
\hline 10 & 508 & $\mathbf{1 8 2}$ \\
\hline Total & \multicolumn{3}{|l|}{ Sumber $:$ Pengolah Data Excel } \\
\hline
\end{tabular}

Tabel 3. Analisa Nilai Rata-Rata Nilai Variabel Likes dan Subscriber Akun YouTube Nike

\begin{tabular}{|l|l|l|}
\hline No & Likes & Subscriber \\
\hline 1 & 167 & \\
\hline 2 & 328 & \\
\hline 3 & 827 & \\
\hline 4 & 105 & \\
\hline 5 & 183 & \\
\hline 6 & 146 & \\
\hline 7 & 75 & \\
\hline 8 & 129 & \\
\hline 9 & 172 & \\
\hline 10 & 118 & $\mathbf{1 . 6 6 0 . 0 0 0}$ \\
\hline Total & $\mathbf{2 2 5}$ & \\
\hline
\end{tabular}


Sumber : Pengolah Data Excel

Tabel 4. Analisa Nilai Rata-Rata Nilai Variabel Likes dan Subscriber Akun YouTube New Balance

\begin{tabular}{|l|l|l|}
\hline No & Likes & Subscriber \\
\hline 1 & 1.900 & \\
\hline 2 & 79 & \\
\hline 3 & 20 & \\
\hline 4 & 22 & \\
\hline 5 & 119 & \\
\hline 6 & 549 & \\
\hline 7 & 4.500 & \\
\hline 8 & 413 & \\
\hline 9 & 17 & $\mathbf{1 1 3 . 0 0 0}$ \\
\hline 10 & 6.500 & $\mathbf{1 . 4 1 2}$ \\
\hline Total & \multicolumn{3}{|c|}{ Sumber : Pengolah Data Excel } \\
\hline
\end{tabular}

Tabel 5. Analisa Nilai Rata-Rata Nilai Variabel Likes dan Subscriber Akun YouTube Converse

\begin{tabular}{|l|l|l|}
\hline No & Likes & Subscriber \\
\hline 1 & 2.000 & \\
\hline 2 & 95 & \\
\hline 3 & 10 & \\
\hline 4 & 49 & \\
\hline 5 & 10 & \\
\hline 6 & 20 & \\
\hline 7 & 288 & \\
\hline 8 & 14 & \\
\hline 9 & 492 & \\
\hline 10 & 57 & $\mathbf{1 3 3 . 0 0 0}$ \\
\hline Total & $\mathbf{3 0 4}$ \\
\hline
\end{tabular}

Sumber : Pengolah Data Excel

Setelah menghitung nilai rata-rata tersebut, maka akan menemukan hasil akhir nilai ratarata dari variabel likes dan subscriber, yaitu :

Tabel 6. Nilai Variabel Pada Akun YouTube 5 Brand Sepatu Terkenal di Dunia

\begin{tabular}{|c|c|c|c|c|c|}
\hline \multicolumn{6}{|c|}{ Tabel Nilai Masing-Masing Variable } \\
\hline Variable & Vans & Adidas & Nike & New Balance & Converse \\
\hline Likes & 2655 & 182 & 225 & 1412 & 304 \\
\hline Subscriber & 612000 & 931000 & 1660000 & 113000 & 133000 \\
\hline
\end{tabular}

Sumber : Pengolah Data Excel

Pada akun YouTube terdapat 10 rasio yang relevan digunakan untuk mengukur kredibilitas pada masing-masing akun. Namun pada penelitian kali ini hanya berfokus untuk 
menghitung Likes to Subscriber Ratio. Untuk menghitung kredibilitas dari masing-masing akun YouTube setiap brand sepatu, peneliti menghitung dengan cara : variabel 1 akan dibagi dengan variabel 2, sehingga ditemukan hasil analisa dari rasio tersebut, yaitu :

Tabel 7. Hasil Perhitungan Rasio Akun YouTube

\begin{tabular}{|l|l|l|l|l|l|l|}
\hline \multicolumn{2}{|l|}{ Tabel Rasio } \\
\hline No & RATIO & Vans & Adidas & Nike & New Balance & Converse \\
\hline 1 & $\begin{array}{l}\text { Likes to } \\
\text { Subscriber } \\
\text { Ratio }\end{array}$ & 0,00433824 & 0,00019549 & 0,00013554 & 0,01249558 & 0,00228571 \\
\hline
\end{tabular}

Sumber : Pengolah Data Excel

Likes to Subscriber Ratio memiliki karakteristik yang tinggi, yang memiliki arti semakin tinggi nilai yang dihasilkan maka semakin baik kredibilitas dari performa akun tersebut. Untuk memberikan peringkat pada masing-masing Brand Sepatu, peneliti memberikan angka 5 kepada brand yang mendapatkan nilai tertinggi dan angka 1 untuk brand sepatu yang mendapatkan nilai terendah. Berikut ini merupakan tabel urutan nilai yang dihasilkan oleh masing-masing brand sepatu, yaitu :

Tabel 8. Nilai Rasio Akun YouTube 5 Brand Sepatu Terkenal di Dunia

\begin{tabular}{|c|c|c|c|c|}
\hline Vans & Adidas & Nike & New Balance & Converse \\
\hline 4 & 2 & 1 & 5 & 3 \\
\hline
\end{tabular}

Dari Tabel Nilai Rasio Akun YouTube 5 Brand Sepatu Terkenal di Dunia dapat disimpulkan bahwa New Balance mendapatkan nilai tertinggi untuk rasio Likes to Subscriber. Sedangkan akun YouTube Nike mendapatkan nilai terendah untuk rasio ini. Jadi, pada penelitian ini New Balance memiliki kredibilitas performa yang lebih baik dibandingkan dengan brand sepatu yang lainnya.

\section{KESIMPULAN}

Tujuan dari penelitian ini adalah untuk mengetahui kredibilitas performa dari akun YouTube 5 Brand Sepatu Terkenal di Dunia menggunakan Likes to Subscriber Ratio. 5 Brand Sepatu tersebut diantaranya yaitu : Vans, Adidas, Nike, New Balance, Converse. Dari kelima brand sepatu tersebut dapat disimpulkan bahwa :

1. Peringkat pertama diraih oleh brand New Balance dengan nilai tertinggi yaitu 0,01249558

2. Peringkat kedua diraih oleh brand Vans dengan nilai 0,00433824

3. Peringkat ketiga diraih oleh brand Converse dengan nilai 0,00228571

4. Peringkat keempat diraih oleh brand Adidas dengan nilai 0,00019549

5. Peringkat kelima diraih oleh brand Nike dengan nilai terendah yaitu 0,00013554 


\section{DAFTAR PUSTAKA}

Begini sejarah 5 brand sepatu terkenal dunia. (n.d.).

IndiHome - Wikipedia bahasa Indonesia, ensiklopedia bebas. (n.d.). https://id.wikipedia.org/wiki/IndiHome

Permana, I. P. H. (2021). Analisis Rasio Pada Akun Youtube Untuk Penelitian Kualitatif Menggunakan Metode Ekploratif. 15(1), 40-48.

Sinaga, E. M. (2020). Channel YouTube Untuk Meningkatkan Customer Engagement . Seminar Nasional Teknologi Komputer \& Sains (SAINTEKS), 607-610. http://prosiding.seminar-id.com/index.php/sainteks/article/view/507/505

Thanissaro, P. N., \& Kulupana, S. (2015). Buddhist teen worldview: Some normative background for health professionals. Contemporary Buddhism, 16(1), $28-42$. https://doi.org/10.1080/14639947.2015.1006801

Variabel Penelitian Adalah_Pengertian, Jenis, Contoh - Uji Statistik. (n.d.).

Yunita, D., Nazaruddin, A., \& Nailis, W. (2019). Pengaruh Youtube Advertising terhadap Brand Awareness dan Purchase Intention. Jurnal Manajemen Dan Kewirausahaan, 7(1). https://doi.org/10.26905/jmdk.v7i1.2538 